\title{
BDSM as Sexual Orientation: A Comparison to Lesbian, Gay, and Bisexual Sexuality
}

\author{
Tess M. Gemberling, M.A. \\ University of Alabama \\ Robert Cramer, Ph.D. \\ Old Dominion University \\ Rowland S. Miller, Ph.D. \\ Sam Houston State University
}

One less common and more stigmatized form of sexuality is BDSM, which is an umbrella term for consensual practices that involve, but are not limited to, bondage and discipline (B\&D), dominance and submission (D\&s), and sadomasochism (S\&M). Focusing on one of many different conceptualizations, BDSM is comprised of a power dynamic between partners enacted through various activities (for an inclusive list, see Sandnabba et al., 1999; Weinberg et al., 1984). However, beyond being recently accepted as non-pathological, research has yet to reach consensus on BDSM's nature and development. Specifically, although theories describing its origin abound, it remains unclear whether BDSM is best conceptualized as a sexual behavior, sexual attraction, sexual identity, and/or sexual orientation for those who practice for sexual purposes. Accordingly, the present paper outlines a common framework of sexuality while presenting an alternative yet complementary theory: Consistent with a sex-positive framework, BDSM may be best conceptualized as another form of sexual orientation for a percentage of practitioners.

\section{A Complementary Alternative Theory of BDSM Practice}

Historically, sexual orientation has largely referred to the preferred gender or sex of potential sexual partners (i.e., preference for males and/or females [or neither]), although it has been recently extended to other target characteristics (e.g., for age: preference for children, adolescents, and/or adults; Seto, 2012). But, consistent with emerging theories, such as van Anders's (2015) Sexual Configurations Theory, we believe sexual orientation is more inclusive than currently considered. While a comprehensive discussion is not presented here, one area posed for incorporation is the preferred power dynamic between sexual partners (i.e., preference for dominance and/or submission [or neither]). To evaluate such applicability, we examine BDSM sexuality as a prime example within three expressions of sexual orientation - sexual behavior, sexual attraction, and sexual identity. Because sexual orientation has only been thoroughly analyzed in respect to lesbian, gay, bisexual, and other queer sexualities (for convenience, LGB), such will serve as the foundation for comparison.

\section{Sexual Behavior}

The most concrete aspect of sexuality is sexual behavior, which can be defined as engagement in a range of sexual activities (i.e., kissing to sexual intercourse), but is often limited to 
"involvement in (minimally) genital contact" (Savin-Williams, 2009, p. 8). Below, three different aspects of sexual behavior are discussed: 1) onset, 2) consistency, and 3) stability.

Onset. While first sexual activity with other-sex individuals can occur simultaneously, before, or after first same-sex experience, LGB individuals' first same-sex sexual experience often occurs in their late adolescence to early twenties (e.g., Calzo et al., 2011; Diamond, 1998; Floyd \& Bakeman, 2006; Parks, 1999). In contrast, with first non-BDSM sex consistently arising beforehand, practitioners' first BDSM experience frequently transpires in their early to midtwenties (Moser \& Levitt, 1987; Sandnabba et al., 1999).

Consistency. Same-sex sexual activity is highest among lesbian and gay individuals, intermediate among bisexual individuals, and lowest among heterosexual individuals (Ellis et al., 2005). However, a significant percentage of gay and lesbian individuals (e.g., 66.3\% of gay men and $89 \%$ of lesbian women) report sexual experience with the other sex during their lifetimes (e.g., Diamond, 2000; Ellis et al., 2005; Matthews et al., 2006; Smiler et al., 2011). As expected, BDSM practitioners engage in BDSM-related activities at higher rates than non-practitioners (Gosselin \& Wilson, 1980). However, the vast majority (e.g., 95.1\%, 88.8\%) of practitioners continually have, and enjoy, non-BDSM sex (Connolly, 2006; Sandnabba et al., 1999; Weinberg et al., 1984). Also, practitioners' specific roles are often flexible by various circumstances (e.g., partner's wishes, mood, partner's gender), with a substantial minority of exclusively dominant (e.g., 25\%) or submissive (e.g., 36.3\%) practitioners stating they could take the other role on isolated occurrences (Sandnabba et al., 1999; Simula, 2012; Weinberg et al., 1984).

Stability. Across the years, a proportion of LGB individuals report changes in their sexual behavior (e.g., approximately half in a six-year period; Diamond, 2008; Dickson et al., 2013; Kinnish, 2003). Although no located literature examined the stability of BDSM vs. non-BDSM activities, behaviors within BDSM practice have received empirical attention. Just as same-sex sexual experience follows a general pattern (e.g., kissing then intercourse; Smiler et al., 2011), BDSM practice progresses in a common sequence, with practitioners appearing to move on a scale of intensity, beginning with less intense behaviors and advancing to more intense behaviors (Santtila et al., 2002).

\section{Sexual Attraction}

Also manifesting as other constructs such as arousal, interest or fantasy, sexual attraction can be conceptualized as an "intense, physiological, uncontrollable erotic or sexual desire" (SavinWilliams, 2009, p. 8). Below, three different aspects of sexual attraction are discussed: 1) onset, 2) exclusivity, and 3) stability.

Onset. For LGB individuals, becoming aware of same-sex attraction frequently arises during adolescence (e.g., Calzo et al., 2011; Diamond, 1998; Drasin et al., 2008; Floyd \& Bakeman, 2006; Parks, 1999). In contrast, BDSM practitioners often become cognizant of their BDSM interests during their late teens or early twenties (Breslow et al., 1985; Levitt et al., 1994; Sandnabba et al., 1999; Spengler, 1977).

Exclusivity. As expected, rates of same-sex attraction are highest among lesbian and gay individuals, intermediate among bisexual individuals, and lowest among heterosexual individuals (e.g., Diamond, 2008; Ellis et al., 2005; Kinnish, 2003; Rust, 1992). But exclusivity in sexual 
interest is not as common as may be expected (Diamond, 2000; Ellis et al., 2005; Matthews et al., 2006; Rust, 1992). Instead, collectively, gay and lesbian individuals experience largely predominant same-sex attraction with extremely minor other-sex attraction (Diamond, 2000; Kinnish, 2003). In comparison, various levels of exclusivity also exist in BDSM attraction: Approximately a fifth of BDSM practitioners report exclusive attraction to BDSM sex (Spengler, 1977; Taylor \& Ussher, 2001). Slightly more than half of practitioners rate BDSM sexual activity as more satisfying and a tenth to third report only BDSM sexual activity can satisfy (Moser \& Levitt, 1987; Sandnabba et al., 1999; Weinberg et al., 1984). Within roles, approximately a third to half of BDSM practitioners report exclusive attraction to dominance or submission (Breslow et al., 1985; Connolly, 2006; Sandnabba et al., 1999; Spengler, 1977).

Stability. Sexual attraction within LGB sexuality has shown instability, with more than half of LGB individuals reporting changes in their sexual or romantic attraction (Kinnish, 2003; Stokes et al., 1997). Regrettably, information on the stability of BDSM vs. non-BDSM interest was not located. However, fluctuation in role preference has been examined: Approximately half remained stable in their preference, while a fifth became more dominant and a fifth became more submissive (Sandnabba et al., 1999).

\section{Sexual Identity}

Sexual identity is the term individuals use to describe their own sexual orientation, but it often also incorporates beliefs, feelings, and actions associated with such identification (Martos et al., 2014; Mohr \& Fassinger, 2000; Savin-Williams, 2009). Below, three different aspects of sexual identity are discussed: 1) onset, 2) development, and 3) stability.

Onset. Individuals usually first adopt an LGB identity during their late adolescence or early adulthood (Calzo et al., 2011; Drasin et al., 2008; Floyd \& Bakeman, 2006; Parks, 1999). For BDSM, practitioners' first age of "recognizing the S/M inclination and adoption of an S/Moriented identity" frequently occurs during thier mid-twenties (Moser \& Levitt, 1987, p. 328).

Development. Focusing on one of many possible theories, Mohr and Kendra (2011) identified eight dimensions of an LGB identity, which also appear in the BDSM literature: Concealment motivation (i.e., wanting to remain private about one's LGB identity) - BDSM practitioners engage in a range of concealment, from absolute concealment to absolute openness (Stiles \& Clark, 2011). Internalized homonegativity (i.e., dismissing one's LGB identity through heterosexist views) - A small percentage (e.g., 5.8\%, 12.5\%, 20\%) of practitioners wish to renounce their BDSM interests (Levitt et al., 1994; Moser \& Levitt, 1987; Spengler, 1977). Acceptance concerns (i.e., anxiety concerning applicable social stigma) - Many practitioners have noted they fear harassment or disapproval for their BDSM interests and behaviors (Wright, 2008). Identity centrality (i.e., considering one's LGB identity to be central to general identity) Practitioners can self-identify along a continuum, from weak identification to episodic identification to strong identification (Chaline, 2010).

Stability. Significant portions of LGB individuals experience changes in their sexual identity, although rates widely vary (e.g., 0-75\% over 6-year, 10-year, or lifetime periods (Dickson et al., 2013; Kinnish et al., 2005; Mock \& Eibach, 2012). Literature on BDSM identity stability was not located. Fluctuation has been identified (Newmahr, 2010), but it has yet to be quantified. 


\section{Correlations between Sexual Behavior, Attraction, and Identity}

Although the previous discussion may present a disparate picture among sexual orientation components, correlations between sexual behavior, attraction, and identity are high (e.g., Pattatucci \& Hamer, 1995; Savin-Williams, 2014). Further, apparent deviations from strong associations are often explained by certain patterns. For instance, within LGB sexuality, it is likely that lesbian-identified women who engage in sexual activity with men do so because they are attracted to males to a significant, but small, degree (Diamond, 2000). This same arrangement may arise for BDSM sexuality. Because BDSM practitioners do not frequently experience exclusive attraction to BDSM sex, engagement in non-BDSM sex is possibly explained by existing interest in such sexual activity. Accordingly, even when initially presenting as inconsistent, the combination of the factors often cleanly resolve when including all available information. The connections between the facets of LGB sexual orientation, and assumingly BDSM sexuality as well, are possibly best explained by the statement: "Fluidity in sexual identity is not random or arbitrary but reflects [...] attempts to fit a wide range of experiences into a comparatively narrow model of sexuality" (Diamond, 2000, p. 247).

\section{BDSM as a Sexual Orientation}

Even with the many similarities between the two, it is not suggested BDSM sexuality is equivalent to LGB sexuality. They are not the same for many reasons, but the utmost difference between the two sexualities is their focus. It may be that a LGB sexual orientation denotes a sexual orientation based on target gender (in other words, interest in males vs. females vs. both [or neither]) and a BDSM sexual orientation denotes a sexual orientation based on power dynamic (in other words, interest in dominance vs. submission vs. both [or neither]; Weinberg et al., 1984). Therefore, expressions of a BDSM sexual orientation would revolve around a particular power dynamic: engaging in behaviors that generate a certain power dynamic, experiencing attraction towards acts with a certain power dynamic, and adopting an identity that conveys a certain power dynamic. For many practitioners, if all three expressions are present, when the sexual interest is pervasive, it may be best to consider them oriented to their preferred power dynamic. However, such is likely to vary by specific individual (e.g., something best regarded as a sexual behavior by one person may be best regarded as a sexual orientation by another) and remain contingent on a variety of personal or social circumstances (e.g., being unable to locate a partner will bar enacting the orientation in behavior).

Importantly, a BDSM orientation and LGB orientation are not mutually exclusive. Instead, BDSM likely constitutes a distinct yet compatible sexual orientation that appears to be as complex and diverse as LGB sexuality when compared on behavior, attraction, and identity. Although different in subject, both aspects can be considered integral to an individual's sexual functioning. It would be impractical to conceptualize sexuality without both included. Indeed, sexual orientation based on power dynamic may be more commonplace than presently discussed. Presumably, BDSM is only one manifestation of such an orientation. An orientation based on power dynamic is likely to exist outside the formal practice of BDSM in a number of disparate and diverse presentations. Further, BDSM, or power dynamic in general, is only one example of an expanded definition of sexual orientation. Many more variables may also constitute sexual orientations in their own right, no matter if they are characteristics of the target (e.g., gender), the interaction with the target (e.g., power dynamic), or anything else. 


\section{Practitioners' Perspective.}

Complementing the research reviewed above, some of those who know the sexuality best, the practitioners themselves, have described their practice as a sexual orientation:"[BDSM] is definitely an orientation in the same way my sexual orientation is not a sexual choice, it's just who I am" (Weiss, 2006, p. 235). "Kink is often so fundamental to our sexual identities that it has to be, at least in some cases, an orientation." (Keenan, 2014, pp. 15). Further, one of the largest U.S. organizations for those with alternative sexual or romantic interests, the National Coalition for Sexual Freedom (NCSF), describes BDSM as a sexual orientation (or behavior) in their explanation of the sexuality (NCSF, n.d.).

\section{Concluding Remarks}

Yet, as always, more empirical and theoretical consideration is needed to support the presented theory. Further attention has implications for both science and society. A sounder framework for BDSM may answer outstanding empirical questions concerning the definition of BDSM practice. In turn, the enhanced knowledge may contribute to a more tolerant social climate for BDSM practitioners. In addition, the process of weighing the appropriateness of various labels (e.g., behavior, attraction, identity, orientation) can be repeated with other sexual facets to continue exploring the breath of sexual orientation. This, coupled with a sex-positive perspective, may create a more knowledgeable and, most importantly, more accepting world within sexuality.

\section{References}

Breslow, N., Evans, L. E., \& Langley, J. (1985). On the prevalence and roles of females in the sadomasochistic subculture: Report of an empirical study. Archives of Sexual Behavior, 14, 303-317.

Calzo, J. P., Antonucci, T. C., Mays, V. M., \& Cochran S. D. (2011). Retrospective recall of sexual orientation identity development among gay, lesbian, and bisexual adults. Developmental Psychology, 47, 1658-1673.

Chaline, E. R. (2010). The construction, maintenance, and evolution of gay SM sexualities and sexual identities: A preliminary description of gay SM sexual identity practices. Sexualities, 13, 338-356.

Connolly, P. H. (2006). Psychological functioning of bondage/dominance/sado-masochism (BDSM) practitioners. Journal of Psychology \& Human Sexuality, 18, 79-120.

Diamond, L. M. (1998). Development of sexual orientation among adolescent and young adult women. Developmental Psychology, 34, 1085-1095.

Diamond, L. M. (2000). Sexual identity, attractions, and behavior among young sexual-minority women over a 2-year period. Developmental Psychology, 36, 241-250.
Diamond, L. M. (2008). Female bisexuality from adolescence to adulthood: Results from a 10-year longitudinal study. Developmental Psychology, 44, 5-14.

Dickson, N., van Roode, T., Cameron, C., \& Paul, C. (2013). Stability and change in same-sex attraction, experience, and identity by sex and age in a New Zealand birth cohort. Archives of Sexual Behavior, 42, 753-763.

Drasin, H., Beals, K. P., Elliott, M. N., Lever, J., Klein, D. J., \& Schuster, M. A. (2008). Age cohort differences in the developmental milestones of gay men. Journal of Homosexuality, 54, 381-399.

Ellis, L., Robb, B., \& Burke, D. (2005). Sexual orientation in United States and Canadian college students. Archives of Sexual Behavior, 34, 569-581.

Floyd, F. J., \& Bakeman, R. (2006). Coming-out across the life course: Implications of age and historical context. Archives of Sexual Behavior, 35, 287-296.

Gosselin, C., \& Wilson, G. (1980). Sexual variations: Fetishism, sadomasochism and Transvestism. New York: Simon and Schuster. 
Keenan, J. (2014, August 18). Is kink a sexual orientation? Slate. Retrieved from http://www.slate.com/blogs/outward/2014/0 8/18/is_kink_a_sexual_orientation.html

Kinnish, K. K. (2003). Gender differences in the flexibility of sexual orientation: Changes over time in sexual identity and multidimensional ratings of orientation (Doctoral Dissertation). Retrieved from PsycINFO. (2003-95018-132)

Kinnish, K. K., Strassberg, D. S., \& Turner, C. W. (2005). Sex differences in the flexibility of sexual orientation: A multidimensional retrospective assessment. Archives of Sexual Behavior, 34, 173-183.

Levitt, E. E., Moser, C., \& Jamison, K. V. (1994). The prevalence and some attributes of females in the sadomasochistic subculture: A second report. Archives of Sexual Behavior, 23, 465-473.

Martos, A. J., Nezhad, S., \& Meyer, I. H. (2014). Variations in sexual identity milestones among lesbians, gay men, and bisexuals. Sexuality Research and Social Policy. Advance online publication.

Matthews, A. K., Hughes, T. L., \& Tartaro, J. (2006). Sexual behavior and sexual dysfunction in a community sample of lesbian and heterosexual women. In A. M. Omoto \& H. S. Kurtzman (Eds.), Sexual orientation and mental health: Examining identity and development in lesbian, gay, and bisexual people. (pp. 185-205). Washington, DC: American Psychological Association.

Mock, S. E., \& Eibach, R. P. (2012). Stability and change in sexual orientation identity over a 10 -year period in adulthood. Archives of Sexual Behavior, 41, 641-648.

Mohr, J., \& Fassinger, R. (2000). Measuring dimensions of lesbian and gay male experience. Measurement and Evaluation in Counseling and Development, 33, 66-90.

Mohr, J. J., \& Kendra, M. S. (2011). Revision and extension of a multidimensional measure of sexual minority identity: Lesbian, gay, bisexual identity scale. Journal of Counseling Psychology, 58, 234-245.

Moser, C. \& Levitt, E. E. (1987). An exploratorydescriptive study of a sadomasochistically oriented sample. The Journal of Sex Research, 23, 322-337.

Newmahr, S. (2010). Rethinking kink: Sadomasochism as serious leisure. Qualitative Sociology, 33, 313-331.

Parks, C. A. (1999). Lesbian identity development: An examination of differences across generations. American Journal of Orthopsychiatry, 69, 347-361.

Pattatucci, A. M. L., \& Hamer, D. H. (1995). Development of familiarity of sexual orientation in females. Behavior Genetics, 25, 407-420.

Richters, J., de Visser, R. O., Rissel, C. E., Grulich, A. E., \& Smith, A. M. A. (2008).

Demographic and psychosocial features of participants in bondage and discipline, "sadomasochism" or dominance and submission (BDSM): Data from a national survey. The Journal of Sexual Medicine, 5, 1660-1668.

Rust, P. C. (1992). The politics of sexual identity: Sexual attraction and behavior among lesbian and bisexual women. Social Problems, 39, 366-386.

Sandnabba, N. K., Santtila, P., \& Nordling, N. (1999). Sexual behavior and social adaption among sadomasochistically-oriented males. The Journal of Sex Research, 36, 273-282.

Santtila, P., Sandnabba, N. K., Alison, L., \& Nordling, N. (2002). Investigating the underlying structure in sadomasochistically oriented behavior. Archives of Sexual Behavior, 31, 185-196.

Savin-Williams, R. C. (2009). How many gays are there? It depends. In D. A. Hope (Ed.), Contemporary Perspectives on Lesbian, Gay and Bisexual Identities (p. 5-41). New York: Springer.

Savin-Williams, R. C. (2014). An exploratory study of the categorical versus spectrum nature of sexual orientation. Journal of Sex Research, $51,446-453$.

Seto, M. C. (2012). Is pedophilia a sexual orientation? Archives of Sexual Behavior, 41,231-236.

Simula, B. L. (2012). Does bisexuality 'undo' gender? Gender, sexuality, and bisexuality behavior among BDSM participants. Journal of Bisexuality, 12, 484-506.

Smiler, A. P., Frankel, L. B. W., \& Savin-Williams, R. C. (2011). From kissing to coitus? Sex-of partner differences in the sexual milestone achievement of young men. Journal of Adolescence, 34, 727-735.

Spengler, A. (1977). Manifest sadomasochism of males: Results of an empirical study. Archives of Sexual Behavior, 6, 441-455.

Stiles, B. L., \& Clark, R. E. (2011). BDSM: A subcultural analysis of sacrifices and delights. Deviant Behavior, 32, 158-189. 
Stokes, J. P., Damon, W., \& McKirnan, D. J. (1997). Predictors of movement toward homosexuality: A longitudinal study of bisexual men. Journal of Sex Research, 30, 203-213.

Taylor, G. W., \& Ussher, J. M. (2001). Making sense of S\&M: A discourse analytic account. Sexualities, 4, 293-314.

van Anders, S. M. (2015). Beyond sexual orientation: Integrating gender/sex and diverse sexualities via sexual configurations theory. Archives of Sexual Behavior. Advance online publication.

Weinberg, T. S., Williams, C. J., \& Moser, C. (1984). The social constitutes of sadomasochism. Social Problems, 31, 379-389.
Weiss, M. D. (2006). Working at play: BDSM sexuality in the San Francisco bay area. Anthropologica, 48, 229-245.

Wright, S. (2008). Second nation survey of violence \& discrimination against sexual minorities. Baltimore, MD: National Coalition for Sexual Freedom 